\title{
Comparison of Calcium and Barium Microcapsules as Scaffolds in the Development of Artificial Dermal Papillae
}

\author{
Yang Liu, ${ }^{1}$ Changmin Lin, ${ }^{1}$ Yang Zeng, ${ }^{1}$ Haihong Li, ${ }^{2}$ Bozhi Cai, ${ }^{3}$ Keng Huang, \\ Yanping Yuan, ${ }^{1}$ and $\mathrm{Yu} \mathrm{Li}^{3}$ \\ ${ }^{1}$ Department of Histology and Embryology, Shantou University Medical College, Shantou, Guangdong 515000, China \\ ${ }^{2}$ Department of Burn and Plastic Surgery, The Second Affiliated Hospital, Shantou University Medical College, Shantou, \\ Guangdong 515000, China \\ ${ }^{3}$ Tissue Engineering Laboratory, The First Affiliated Hospital, Shantou University Medical College, Shantou, Guangdong 515000, China \\ ${ }^{4}$ Department of Emergency, The Second Affiliated Hospital, Shantou University Medical College, Shantou, Guangdong 515000, China
}

Correspondence should be addressed to Yu Li; yulisci@163.com

Received 27 October 2015; Revised 11 January 2016; Accepted 27 January 2016

Academic Editor: Richard Tucker

Copyright (C) 2016 Yang Liu et al. This is an open access article distributed under the Creative Commons Attribution License, which permits unrestricted use, distribution, and reproduction in any medium, provided the original work is properly cited.

This study aimed to develop and evaluate barium and calcium microcapsules as candidates for scaffolding in artificial dermal papilla. Dermal papilla cells (DPCs) were isolated and cultured by one-step collagenase treatment. The DPC-Ba and DPC-Ca microcapsules were prepared by using a specially designed, high-voltage, electric-field droplet generator. Selected microcapsules were assessed for long-term inductive properties with xenotransplantation into Sprague-Dawley rat ears. Both barium and calcium microcapsules maintained xenogenic dermal papilla cells in an immunoisolated environment and induced the formation of hair follicle structures. Calcium microcapsules showed better biocompatibility, permeability, and cell viability in comparison with barium microcapsules. Before 18 weeks, calcium microcapsules gathered together, with no substantial immune response. After 32 weeks, some microcapsules were near inflammatory cells and wrapped with fiber. A few large hair follicles were found. Control samples showed no marked changes at the implantation site. Barium microcapsules were superior to calcium microcapsules in structural and mechanical stability. The cells encapsulated in hydrogel barium microcapsules exhibited higher short-term viability. This study established a model to culture DPCs in 3D culture conditions. Barium microcapsules may be useful in short-term transplantation study. Calcium microcapsules may provide an effective scaffold for the development of artificial dermal papilla.

\section{Introduction}

Hair loss is most pervasive among middle-aged to elderly white men. By the age of 30 years, approximately $30 \%$ of white men are affected by hair loss; by the age of 50 and 70 years, at least 50 and $80 \%$ are affected, respectively $[1,2]$. Current therapeutic management of baldness is via medication (which is not effective) or hair transplantation (which merely redistributes, rather than increasing the existing hairs). Therefore, novel and effective methods to treat hair loss are required.

The dermal papilla (DP) is situated at the base of the hair follicle (HF) and thought to be an important inducer of new HFs. HF formation occurs only once in a lifetime. In previous studies, researchers implanted DP beneath the upper half of amputated vibrissa HFs, then transplanted the DP into a follicular skin, and induced de novo hair growth [3-6]. Cultured dermal papilla cells (DPCs) could reconstitute new functioning DP in vivo. Although transplantation of DP could be a promising treatment option for baldness, the lack of DP with inductive properties is still a major obstacle.

Multilayer aggregated DPCs are essential for HF morphogenesis in vivo $[7,8]$. Regeneration of HF can be achieved by transplanting dense multicellular aggregates or microtissues of DPCs [9].

For sophisticated development of tissues and growth of artificial organs, we must have materials with characteristics that closely emulate nature. In a previous study, we developed the concept of "artificial DP" by enclosing DPCs in an alginate-polylysine-alginate (APA) semipermeable 
membrane, which was then xenotransplanted into mouse ears and Sprague-Dawley rat footpads to induce HF formation and/or visible hair growth $[10,11]$. However, the APA microcapsule is hollow and, when fragmented, the inside cells are exposed to immune cells. Also, studies on the long-term transplantation of artificial DP are lacking.

Animal studies and clinical trials have shown that alginate based products can provide long-term stability, biocompatibility, and viability of transplanted cells [12]. Barium (Ba) is commonly used to increase the mechanical stability. Even low molar concentrations of $\mathrm{Ba}$ in the gel solution can substantially decrease capsule swelling [13]. The other divalent cation usually used is calcium $(\mathrm{Ca})$, which is not associated without cytotoxicity [14].

To determine a good scaffold material for the development of artificial DP, this study investigated the use of Ba and Ca microcapsules.

\section{Material and Methods}

2.1. Animals. The BALB/c mice and Sprague-Dawley rats, 3 to 6 months old and equal number of males and females, were obtained from the Center of Research Animals, Shantou University Medical College. Animals were maintained at the experimental animal center (SPF animal lab), Shantou University Medical College. All experiments were approved by the Ethics Committee on Research Animal Care at Shantou University Medical College (number SUMC2012092).

2.2. Cultivation and DPC Microcapsules. Normal human scalp specimens were obtained from selected patients with face-lift surgeries. DPCs were isolated and cultured as previously described [15]. The DPC-Ba and DPC-Ca microcapsules were prepared by using a specially designed, highvoltage, electric-field droplet generator (designed by the Institute of Cryobiological Engineering, Shanghai University of Science and Technology). In step 1, the cultured DPCs $\left(5 \times 10^{5}\right.$ cells $\left./ \mathrm{mL}\right)$ were suspended in a mixture of $2 \%(\mathrm{w} / \mathrm{v})$ sodium alginate (Sigma), and then spherical droplets were formed by using the high-voltage electric droplet generator with optimized parameters. In step 2, after washing with $0.9 \%$ saline, the droplets were suspended in $1 \%(\mathrm{w} / \mathrm{v})$ polyL-lysine (MW 15000-22000, Sigma) solution for $10 \mathrm{~min}$ and transferred to $0.2 \%(\mathrm{w} / \mathrm{v})$ sodium alginate solution for $4 \mathrm{~min}$. It was then treated with $0.05 \mathrm{M}$ sodium citrate for $6 \mathrm{~min}$ to liquefy the interior gel of the capsules. Ba microcapsules were prepared as in step 1 and washed with $0.9 \%$ saline. Thereafter, microcapsules were cultured with Dulbecco Modified Eagle Medium (DMEM) at $37^{\circ} \mathrm{C}$. The concentrations of $\mathrm{Ba}$ and $\mathrm{Ca}$ required in the microcapsules were $11 \mathrm{~g} / \mathrm{L}$ and $5.2 \mathrm{~g} / \mathrm{L}$ of calcium chloride and barium chloride, respectively.

Microcapsule size was measured under an inverted microscope by using the micrometer. After 2 weeks of cultivation, microcapsules were stained with hematoxylin and eosin for routine histology. The viability of the microencapsulated DPCs was determined by 3-(4,5-dimethylthiazol-2yl)-2,5diphenyl tetrazolium bromide (MTT) assay and Trypan blue staining by the routine process.
2.3. TEM Analysis of the Ultrastructure of $\mathrm{Ba}$ and $\mathrm{Ca} D P C$ Microcapsules. DPC-Ba and DPC-Ca microcapsules were prefixed with $2.5 \%$ glutaraldehyde for 2 hours at 1 to $4^{\circ} \mathrm{C}$ and washed with $0.1 \mathrm{~mol} / \mathrm{L}$ phosphate-buffered saline. This mixture was then treated with $1 \%$ OsO4 solution for 2 hours and washed with $0.1 \mathrm{~mol} / \mathrm{L}$ phosphate-buffered saline. Samples were dehydrated with alcohol and treated with PolyBed 812 resin overnight. Then, they were stained with uranyl acetate and lead citrate and examined by transmission electron microscopy (TEM) with a JEM1400 microscope (JEOL, Japan).

2.4. Analysis of Structural Stability of Microcapsules. About 1,000 each of DPC-Ba and DPC-Ca microcapsules were transferred into beakers and placed on a magnetic force whisk, which was run at $500 \mathrm{r} / \mathrm{min}$. At this speed, the whisk was rotating at high speed, and the microcapsules knocked on the walls of the beaker. Structural stability was assessed by determining change in structural integrity at 10 and $60 \mathrm{~min}$, using a CX31-12 inverted microscope (Olympus, Japan). Then, $1 \mathrm{~mL}$ each of $\mathrm{Ba}$ and $\mathrm{Ca}$ microcapsules of $400 \mu \mathrm{m}$ diameter were injected through the 7\#, 9\#, and 16\# pinheads with maximum hand forces. The integrated microcapsules were counted using a CK2 phase-contrast microscope (Olympus, Japan), and the structural stability of microcapsules was evaluated.

2.5. Permeability of Artificial and Natural Membranes. Different diameter microcapsules were prepared by adjusting the parameters of the high-voltage electric-field droplet generator. The $\mathrm{Ba}$ and $\mathrm{Ca}$ microcapsules were divided into 3 groups based on size ( $n=10$ each): small $(200$ to $399 \mu \mathrm{m})$, medium (400 to $599 \mu \mathrm{m})$, and large $(600$ to $1000 \mu \mathrm{m})$. These microcapsules were incubated with 3 molecular weights of FITC-dextran $(1 \mathrm{mg} / \mathrm{mL}, 10,40$, and $70 \mathrm{kDa}$, resp., Invitrogen). Fluorescence intensities in microcapsules were measured at various time intervals by confocal microscopy (ACAS/Ultima312, Meridian Instruments, USA).

For detailed structure analysis, $\mathrm{Ba}$ and $\mathrm{Ca}$ microcapsules $(n=10), 400 \mu \mathrm{m}$ in diameter, and freshly isolated DP were incubated with $40 \mathrm{kDa}$ FITC-dextran at $37^{\circ} \mathrm{C}$, at various time intervals $(10,20,30,60$, and $120 \mathrm{~min}$, resp.). The fluorescence inside the microcapsules and DP cells was measured from the center and scanned every $5 \mu \mathrm{m}$ for 5 layers by confocal microscopy. The fluorescence signal was analyzed using the Image Analyze software. Each time point was assessed 10 times.

2.6. Biocompatibility Study of Microcapsules. The same number of DPC-Ba and DPC-Ca microcapsules was introduced into the peritoneal cavity of BALB/c mice $(n=8)$. Mice were sacrificed at 2 and 4 weeks, and the microcapsules were retrieved and observed under an inverted microscope.

2.7. Analysis of Hair Follicle Generation by DPC-Ba and DPCCa Microcapsules in Mice Model. Sprague-Dawley rats $(n=$ 42) were anesthetized with ketamine, and the implantation sites were swabbed with $75 \%$ ethanol and $0.9 \%$ saline. About 
$1 \mathrm{~mL}$ of air was injected into the subcutaneous tissue of the hairless regions of rat ears to separate the epidermis and dermis [11]. A $2 \mathrm{~mm}$ incision was made in the right and left ears by using the tip of a scalpel blade. Approximately $0.1 \mathrm{~mL}$ of $\mathrm{Ba}$ or $\mathrm{Ca}$ microcapsules were implanted into the incision on the left ear by using a 16\# injection needle. The incision was closed with the biological glue. Empty microcapsules were implanted into the right ear and were used as the control. Rats with both $\mathrm{Ba}$ and $\mathrm{Ca}$ microcapsules ( $n=12$ each) were sacrificed at $1,2,3$, and 4 weeks. Rats with only Ca microcapsules $(n=18)$ were sacrificed at 12, 16, 20, 24, 28 , and 36 weeks. The implantation sites were biopsied for histological evaluation.

2.8. Histology. Specimens were treated with $4 \%$ paraformaldehyde, dehydrated through a graded series of ethanol, washed with xylene, and embedded in paraffin wax. These treated specimens were cut into $4 \mu \mathrm{m}$ sections and stained with hematoxylin and eosin for routine histological evaluation.

2.9. Statistical Analysis. Data are presented as mean \pm SD. Analysis of structural stability and biocompatibility of the microcapsules were evaluated by 2 -tail Student's $t$-test. A $P$ value $<0.05$ was considered statistically significant.

\section{Results}

3.1. DPC-Ba and DPC-Ca Microcapsule Structure and Viability of Embedded Cells. Microscopy showed that $\mathrm{Ba}$ and $\mathrm{Ca}$ microcapsules were round, with smooth and transparent structure (Figures 1(a) and 1(b)). By adjusting the parameters of the high-voltage electric-field droplet generator to $7.0 \mathrm{kV}$ voltage, injection speed to $55 \mathrm{~mm} /$ hour, and a distance of $10 \mathrm{~mm}$, the diameter of the DPC microcapsules formed was maintained uniform at $0.4 \mathrm{~mm}$. The DPCs embedded within the $\mathrm{Ca}$ microcapsules were either isolated or grouped in small clusters. At 12-hour culture, Ca microcapsules showed multilayered aggregates. For Ba microcapsules, the number of DPCs was constant, and the cells were either isolated or grouped as small clusters. At 24 hours after embedding, viability of microencapsulated cells by Trypan blue staining was $84.4 \%$ for Ca microcapsules and $75.4 \%$ for Ba microcapsules $(P>0.05)$.

Histology of $\mathrm{Ca}$ microcapsules revealed gradual aggregation of DPCs. Concurrently, cells showed secretion of extracellular matrix by hematoxylin and eosin staining (Figures $1(\mathrm{c})$ and $1(\mathrm{~d})$ ), which indicated continuous production of high amounts of glycosaminoglycan, a characteristic feature of the in situ conditions during anagen [2, 16]. For $\mathrm{Ba}$ microcapsules, cells were separate at all times, with no extracellular matrix production.

The TEM analysis revealed that the external microcapsule membrane and DPCs were surrounded by a fibrillar matrix consisting mainly of alginate (Figure 1(e)). TEM analysis also confirmed that the DPCs adhered to the microcapsule membrane for 24 to 72 hours and the cells retained their fine structure for 6-8 weeks under conventional culture conditions. The membrane of the $\mathrm{Ba}$ microcapsules was smooth, with homogeneous and solid contents inside the microcapsules. The DPCs were separate and rounded with the solid alginate (Figure 1(f)).

At 48 hours, the viability of DPCs microencapsulated in $\mathrm{Ba}$ and $\mathrm{Ca}$ microcapsules was $90.5 \%$ and $85.3 \%$, respectively. The MTT assay showed that the density of $\mathrm{Ba}$ and Ca microencapsulated DPCs was initially lower compared with the nonencapsulated DPCs but increased gradually (Figure 2). By day 14, the density of DPCs in Ca microcapsules was close to that of the control group.

3.2. Structural Stability of Ba and Ca Microcapsulated DPCs. The structural stability was significantly higher for Ba compared with $\mathrm{Ca}$ microcapsules during whisking and injection. The numbers of $\mathrm{Ba}$ and $\mathrm{Ca}$ microcapsules that retained structural integrity at $10 \mathrm{~min}$ were $84.8 \%$ and $73.2 \%$, respectively $(P<0.05)$. At $60 \mathrm{~min}$, their numbers were $36.3 \%$ and $12.0 \%$, respectively $(P<0.01)$ (Figure $3(\mathrm{a}))$. The contents inside the $\mathrm{Ca}$ microcapsules escaped when fragmented (Figure 3(b)). However, the cells were retained within the membrane for $\mathrm{Ba}$ microcapsules, even after fragmentation (Figure 3(c)).

The percentages of microcapsules that remained intact following the injection of $400 \mu \mathrm{m}$ Ba microcapsules through the 7\#, 9\#, and 16\# pinheads were $32.8 \%, 54.1 \%$, and $100 \%$, respectively, and those for $\mathrm{Ca}$ microcapsules were $0 \%, 14.6 \%$, and $96.5 \%$, respectively (Figure $3(\mathrm{~d})$ ).

3.3. Permeability of $\mathrm{Ba}$ and $\mathrm{Ca}$ Microcapsule Membranes. To test the permeability of microcapsules to nutrient materials, the microcapsules were treated with FITC-dextran. Confocal microscopy of Ca microcapsules from top to bottom revealed homogenously diffused fluorescence gradually coalescing in sharp concentric circles into the center of microcapsules. Specifically, because of the liquefied alginate core of $\mathrm{Ca}$ microcapsules, the fluorescence could diffuse into the core of Ca microcapsules within $60 \mathrm{~min}$ (Figure 4(a)). However, the $\mathrm{Ba}$ and fresh DP microcapsules both showed significantly lower fluorescence compared to the Ca microcapsules $(P<$ 0.01 ), with no sharp concentric circles (Figure 4(a)). The Ba and fresh DP microcapsules were not completely filled with fluorescence in $120 \mathrm{~min}$. The fluorescence intensity inside $\mathrm{Ca}$ microcapsules was related to the molecular weight of FITC-dextran $(10>40>70 \mathrm{kDa})$ (Figures 4(b), 4(c), and 4(d)). When Ca microcapsules were fragmented, medium and FITC-dextran leaked into microcapsules immediately (Figure 4(e)). However, no FITC-dextran was detected inside the solid medium of Ba microcapsules, even after Ba microcapsules were fragmented (Figure 4(f)). The fluorescence was stronger for $200 \mu \mathrm{m}$ compared with $600 \mu \mathrm{m}$ diameter $\mathrm{Ca}$ microcapsules (Figure 4(g)).

3.4. Biocompatibility of DPC-Ba and DPC-Ca Microcapsules. One week after transplantation into the peritoneal cavity, the retrieval rates of $\mathrm{Ba}$ and $\mathrm{Ca}$ microcapsules were $84.3 \%$ and $78.9 \%$, respectively $(P>0.05)$ (data not shown). After 3 weeks, the retrieval rates were $76.8 \%$ and $70.2 \%$, respectively $(P>0.05)$. After 1 week, the rates of fibrosis for $\mathrm{Ba}$ and $\mathrm{Ca}$ microcapsules were $1.47 \%$ and $2.10 \%(P>0.05)$, respectively. After 3 weeks, the rates of fibrosis were $2.31 \%$ 
$\mathrm{Ca}$

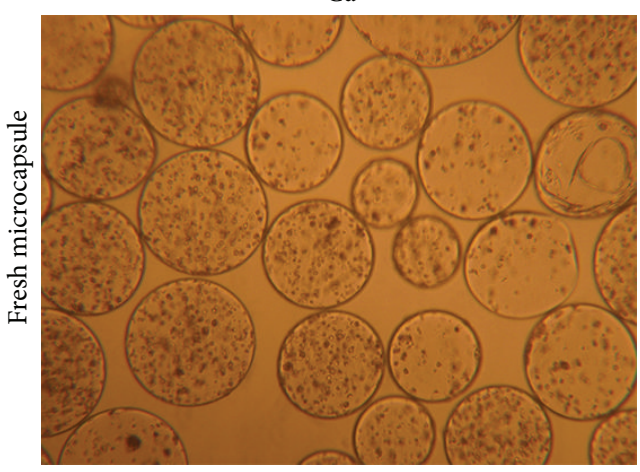

(a)

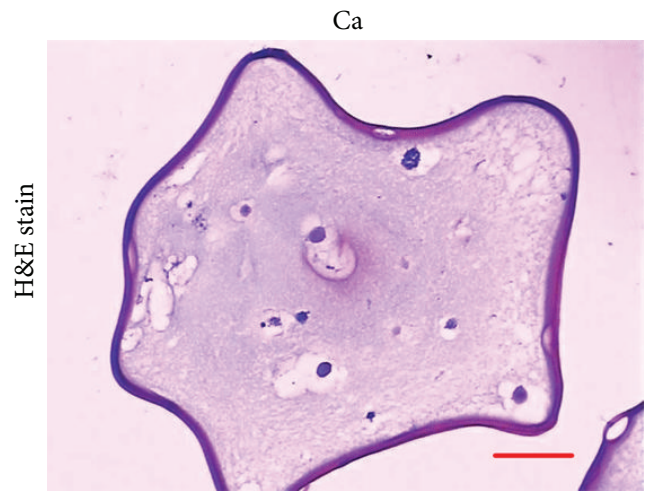

(c)

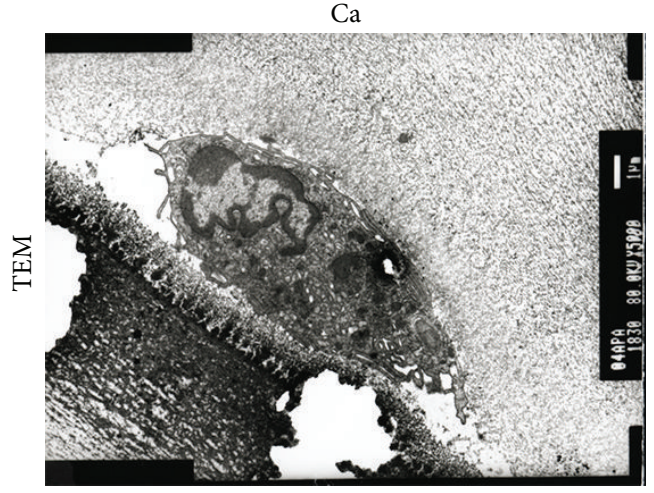

(e)

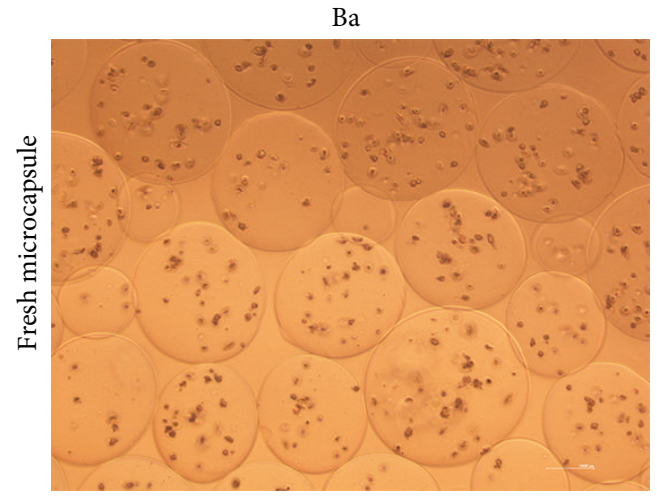

(b)

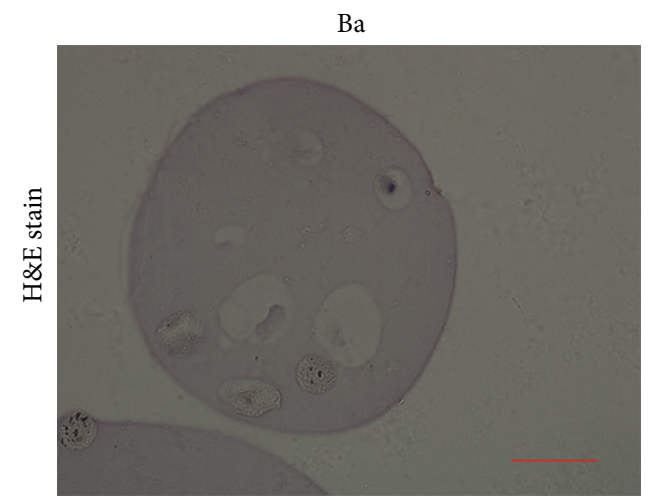

(d)

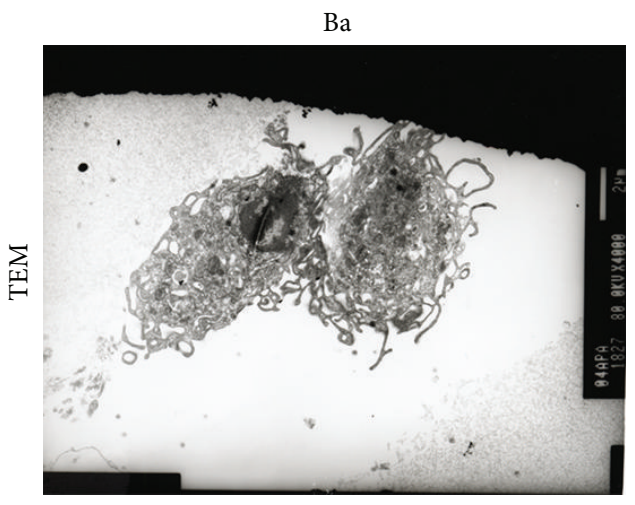

(f)

Figure 1: Ca and Ba DPC microcapsule structure. Microcapsule structures were accessed with light microcopy (a, b). The packaged DP cells and extracellular structures were further studied with H\&E staining $(c, d)$. Transmission electron microscopy was utilized to observed detail structures of microcapsule membrane and inside DP cells (red circles) (e, f). Ca (a) and Ba (b) microcapsules appeared round, smooth, and transparent under inverted microscopy. H\&E staining showed extracellular matrix secreted around cells (red arrow) (c). Ba microcapsules showed scattered cells at all times, with no extracellular matrix (d). TEM confirmed that DPCs adhered to the Ca microcapsule membrane in 24 to 72 hours, and the cells retained their fine structure (e). The membrane of the Ba microcapsules was smooth, with solid and homogeneous core and cells inside showed many microvilli (red arrows) (f). (Bar $=100 \mu \mathrm{m}(\mathrm{a}, \mathrm{b}, \mathrm{c}$, and d), Bar $=1 \mu \mathrm{m}(\mathrm{e}, \mathrm{f})$.)

and 5.85\%, respectively $(P<0.01$, Figure 5(a)). When the microcapsules were fragmented, the cells within the Ca microcapsules escaped (Figure 5(b)) while those within the Ba microcapsules were retained in microcapsule membranes.

\subsection{Functional Study of DPC Microcapsules in Rat Ears}

3.5.1. Short-Term Study (First 12 Weeks). When implanted into hairless regions of SD rat ears, both DPC-Ba and
DPC-Ca microcapsules induced the de novo growth of a large number of HFs in rat ears within 2 to 4 weeks. When compared with $\mathrm{Ba}$ microcapsules, Ca microcapsules showed stronger induction. The induced HF number, size, and visible fibers were significantly greater with $\mathrm{Ca}$ microcapsules compared with Ba microcapsules (Table 1). The number and size of abnormal HF and sebaceous glands were greater with $\mathrm{Ca}$ microcapsules compared with the $\mathrm{Ba}$ microcapsules (Figure 6). The new large HFs in case of Ca microcapsules 
TABLE 1: Numbers of observed hair follicles after microcapsule injection (in single visible field under microscope with 10x amplification).

\begin{tabular}{lcc}
\hline Week & $\mathrm{Ba}$ & $\mathrm{Ca}$ \\
\hline 1 & $7.7 \pm 1.5$ & $13.3 \pm 1.5$ \\
2 & $12.7 \pm 0.6$ & $15.7 \pm 1.5$ \\
3 & $16.0 \pm 1.0$ & $23.0 \pm 2.0$ \\
4 & $11.7 \pm 1.5$ & $20.0 \pm 1.0$ \\
\hline
\end{tabular}

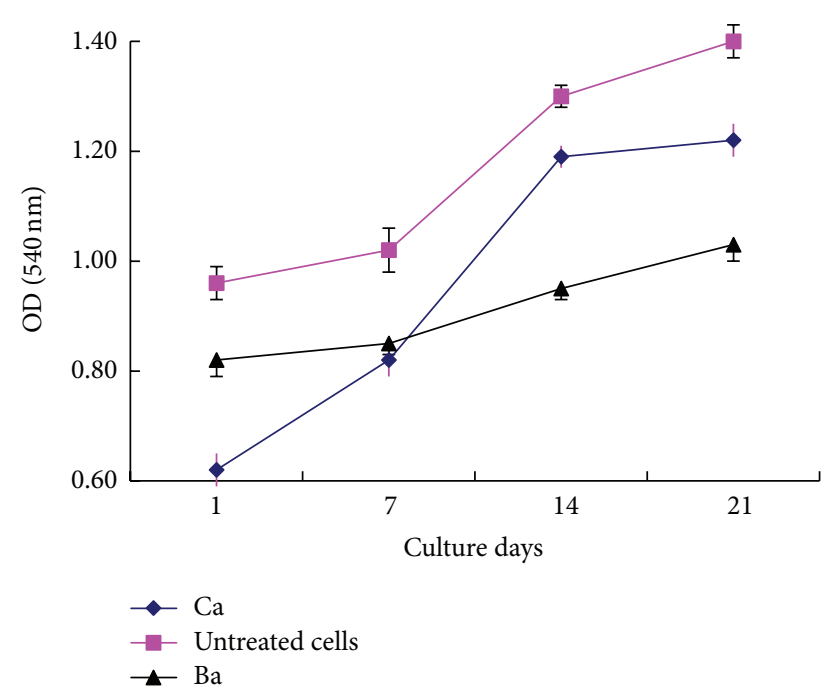

FIGURE 2: Viability and growth of embedded cells. Populations of alive cell in microencapsulated cells and untreated cells were determined by MTT assay. Data are represented as mean \pm SD from 3 experiments.

showed the basic morphological features of human HFs and visible hair fibers at 6 weeks. The longest fibers grew to 7 to $8 \mathrm{~mm}$. These abnormal fibers remained for 3 to 4 weeks and then fell off. Also the large HFs in case of $\mathrm{Ca}$ microcapsules remained until 8 weeks and reduced gradually in number but were absent in Ba microcapsules within 2 to 3 weeks. While the inflammatory cells gathered and blood vessels proliferated at the injected sites during the first week following the transplantation for the $\mathrm{Ba}$ microcapsules, the $\mathrm{Ca}$ microcapsules did not produce these reactions until 24 weeks.

3.5.2. Long-Term Study (12 to 36 Weeks). Interestingly, the DPC-Ca microcapsules showed some changes synchronously in the formation of HFs in rat ears. From 12 to 20 weeks, the number of large HF structures was reduced. From 20 to 32 weeks, only a few abnormal HFs remained (Figures 7(a), 7(b), and $7(\mathrm{c})$ ). Before 20 weeks, only DPC microcapsules were found in the sections with no inflammatory cells around the microcapsules, indicating no serious immune response. From 20 to 36 weeks, the DPC microcapsules were associated with few inflammatory cells and small blood vessel proliferation (Figure 7(h)). After 36 weeks, some DPC microcapsules were surrounded by inflammatory cells and wrapped with fibers (Figure 7(i)). A few abnormal HFs were found in the section. Control samples showed no marked changes at the implantation site (data not shown).

\section{Discussion}

The DP from human scalp is oval, with an approximately 200 to $300 \mu \mathrm{m}$ long axis. Every DP has about 500 cells [16]. The proliferation rate of DPCs was high in vitro, which indicated that enough cells could be harvested for transplantation. Compared with other cells, DPCs have low metabolism for maintaining multilayer aggregation when cultured in vitro [5]. In our previous study, we found that DPCs provided some signals to induce HF reconstruction but not form the structures of new HFs $[10,11]$. Here, we investigated the culture of DPCs in a 3D microenvironment using alginate microcapsules. Several studies have demonstrated the benefits of 3D culture for DP to maintain its HF induction property $[10,11,17]$. In the present study, we compared 2 different alginate microcapsules, the $\mathrm{Ba}$ microcapsules and Ca microcapsules.

Cell viability was better with DPC-Ca microcapsules compared with DPC-Ba microcapsules. The permeability was higher for Ca microcapsules compared with the Ba microcapsules. Also the largest molecule that could permeate through the APA membranes was $<70 \mathrm{kDa}$ for Ca microcapsules but was $<40 \mathrm{kDa}$ for $\mathrm{Ba}$ microcapsules. $\mathrm{Ba}$ and $\mathrm{Ca}$ microcapsules may have different core textures, liquid in case of Ca microcapsules but solid for $\mathrm{Ba}$ microcapsules. This may explain why the DPCs had better viability with Ca microcapsules compared with the Ba microcapsules. The permeability was greater for Ca microcapsules (200 to $400 \mu \mathrm{m}$ ) compared with the fresh DP membranes, which suggested that $\mathrm{Ca}$ microcapsules can maintain DPC viability well. A higher "permeability" allows better passage of small molecules such as nutrients, oxygen, and growth factors and thereby helps keep the cells alive. Furthermore, Ca microcapsules but not $\mathrm{Ba}$ microcapsules secreted extracellular matrix from DPCs. Despite all cells surviving in both alginate microcapsules, cell viability in APA was better for $\mathrm{Ca}$ microcapsules compared with the Ba microcapsules in the long-term study. In another study [18], primary mammalian chondrocytes and intervertebral disc cells maintained higher viability and proliferation rate and produced higher sulfated glycosaminoglycan content when encapsulated in $\mathrm{Ca}$ microcapsules compared to the encapsulation in $\mathrm{Ba}$ alginate.

Biocompatibility was better for Ca microcapsules compared with $\mathrm{Ba}$ microcapsules in the long term following transplantation. $\mathrm{Ba}$ microcapsules have an elastic/gel like core, for better structural stability than Ca microcapsules. If $\mathrm{Ca}$ microcapsules are blocked, the inside cells would be immediately exposed to immune response. In transplanted animals, before 30 weeks, we observed no inflammatory cells in case of $\mathrm{Ca}$ microcapsules. Therefore, $\mathrm{Ca}$ microcapsules could contain and immunoprotect inner cells for a long time.

Although the compatibility between the Ba microcapsules and the receptor was less compared with that with $\mathrm{Ca}$ microcapsules, the Ba microcapsules showed more structural stability when compared with Ca microcapsules. Ba microcapsules may be beneficial in other fields such as short-term induced study or some special sites.

It is worth noticing that, in our biocompatibility and animal implantation assays, both $\mathrm{Ba}$ and $\mathrm{Ca}$ microcapsules 


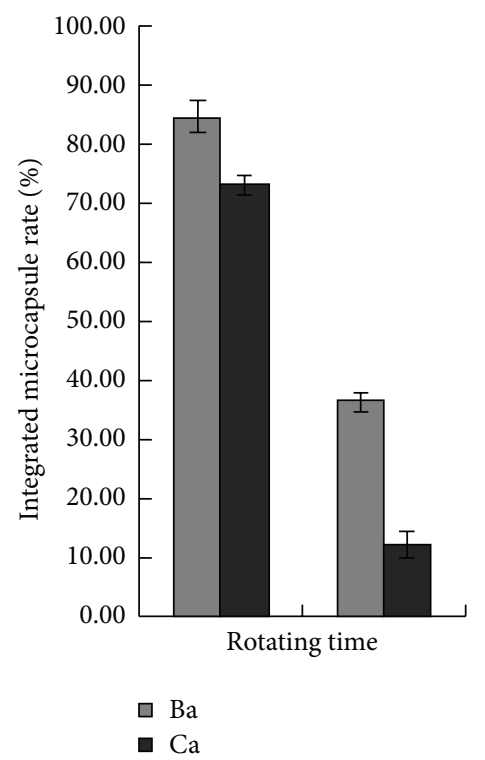

(a)
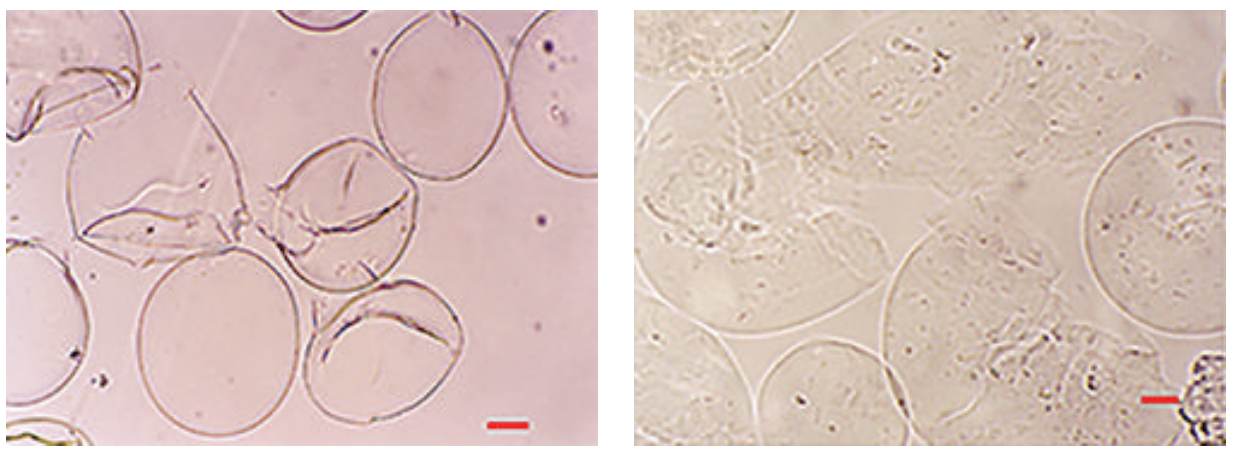

(b)

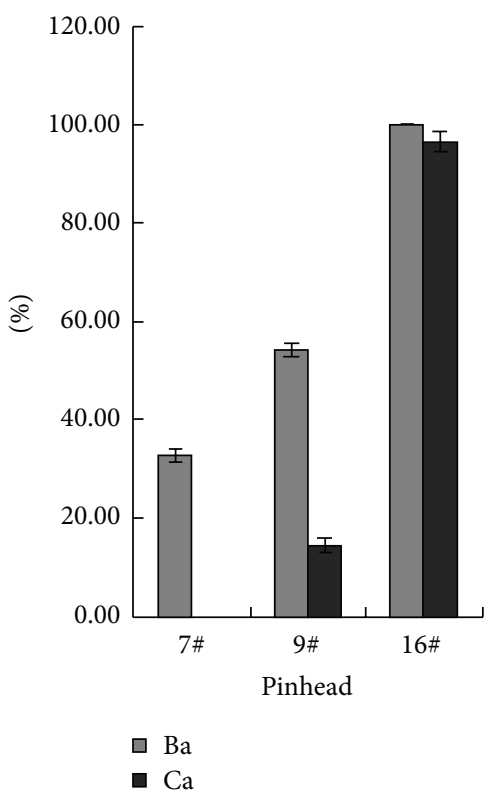

(d)

FIGURE 3: Structural stability microcapsules. Thousands each of DPC-Ba and DPC-Ca microcapsules were assessed by determining change in structural integrity under an inverted microscope at 10 and $60 \mathrm{~min}$ after being stirred in flask (a). Cells inside the fragmented Ca microcapsules escaped (b). Cells were retained inside the membrane of Ba microcapsules, even after fragmentation (c). $1 \mathrm{~mL}$ of Ba and Ca microcapsules of $400 \mu \mathrm{m}$ diameter were injected through 7\#, 9\#, and 16\# pinheads, and integrated microcapsules were counted under a phase-contrast microscope $(d) .(B a r=100 \mu \mathrm{m}$.)

showed resistance to in vivo degradation. These results might be due to large size and the stability of composing materials of microcapsules. In addition, the failure of transplanted animal to keep the hair follicle structure in the long term might also contribute to the stability of microcapsules, resulting in insufficient blood and nutrition supplies. Chemical modifications have been suggested to improve the in vivo degradation of transplant supporting materials [19]. Further related studies are needed to address those issues.
Some studies have shown other 3D culture systems. For instance, long-term 3D histoculture (supported by Gelfoam ${ }^{\circledR}$ ) of whiskers isolated from transgenic mice was established, with nestin driving green fluorescent protein (ND-GFP), and stem cells were shown to traffic from the BA toward the DP area over a 2-week period, extensively growing out onto Gelfoam forming nerve-like structures [20]. Interestingly, the growing whisker sensory nerve was highly enriched in ND-GFP cells which affected its elongation as well as interaction with other nerves, indicating a major impact 

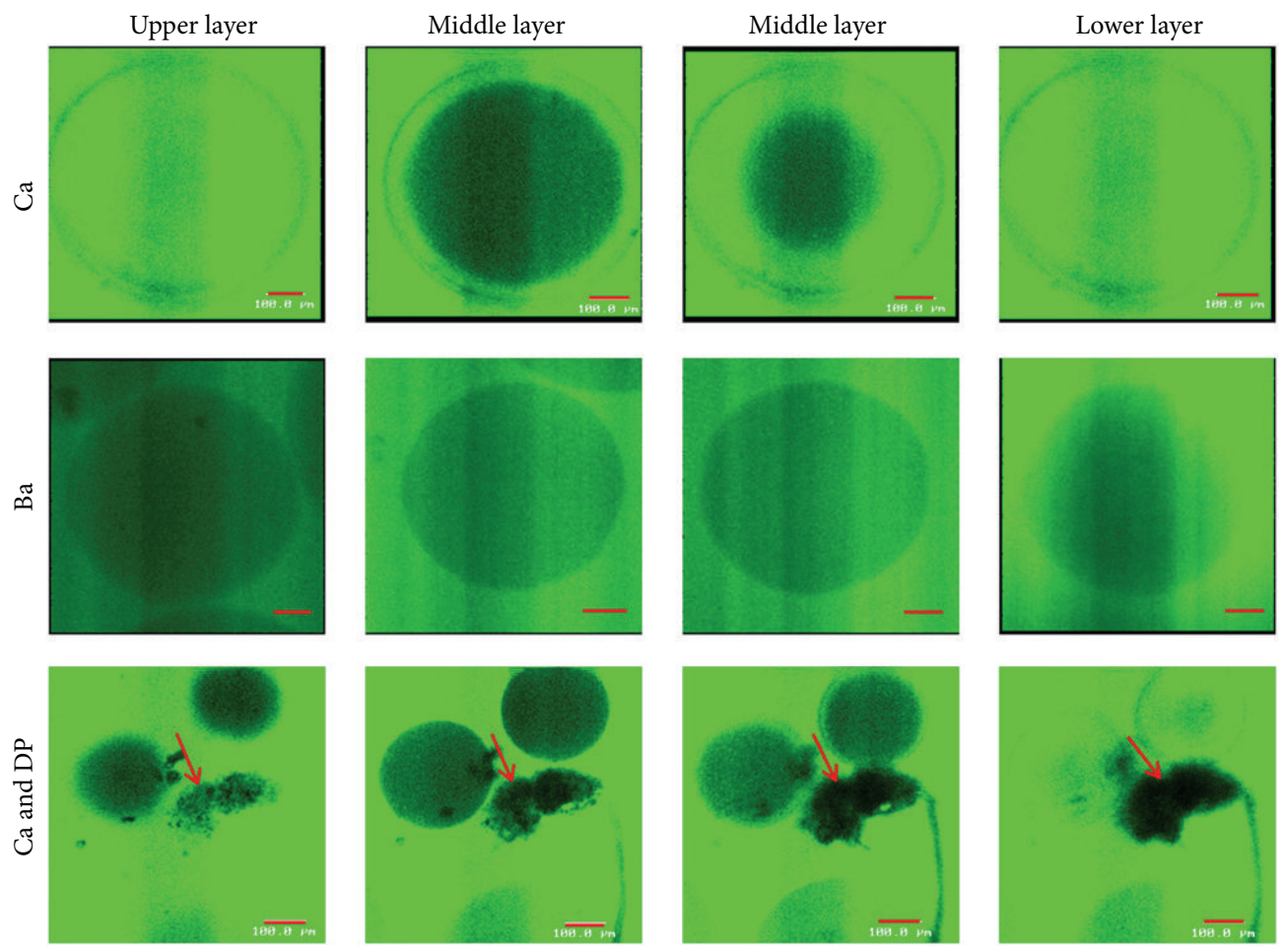

(a)

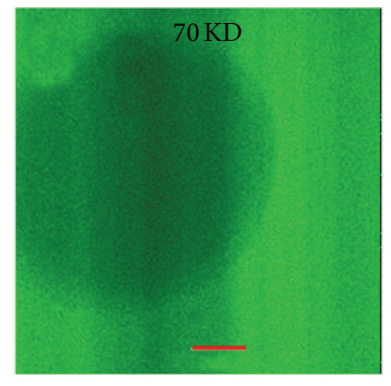

(b)

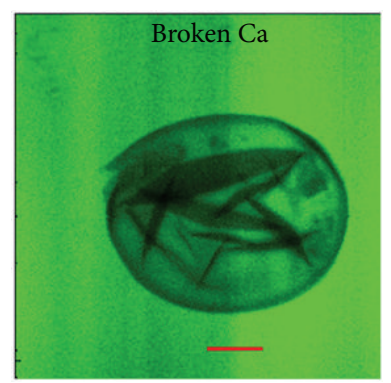

(e)

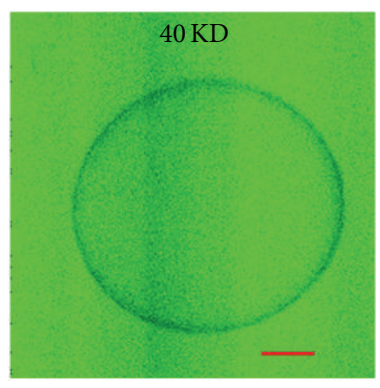

(c)

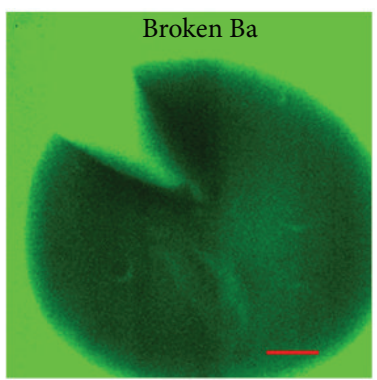

(f)

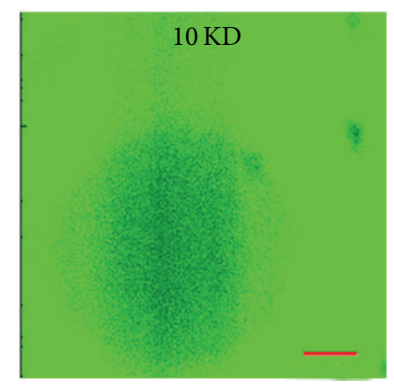

(d)

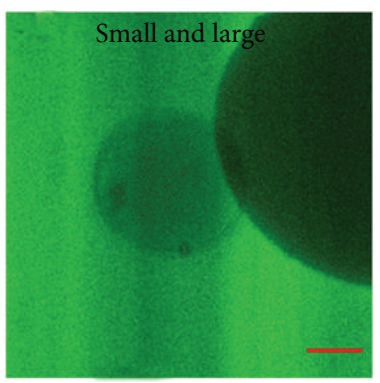

(g)

Figure 4: Permeability of artificial and natural membranes. (a) The diffusion of fluorescence in Ca and Ba microcapsules and fresh DP (red arrow) was monitored by scanning from the center every $5 \mu \mathrm{m} \times 4$ times by confocal microscopy after being permeabilized for 60 min. (b, c, d) The Ca microcapsules permeabilized for 30 minutes with different molecular weight of FITC-dextran. The medium and FITC-dextran entered the broken Ca capsules immediately (e) but not into Ba microcapsules even after fragmentation (f). (g) The fluorescence was stronger for $200 \mu \mathrm{m}$ microcapsules compared with $600 \mu \mathrm{m}$ diameter Ca microcapsules. (Bar $=100 \mu \mathrm{m}$.) 


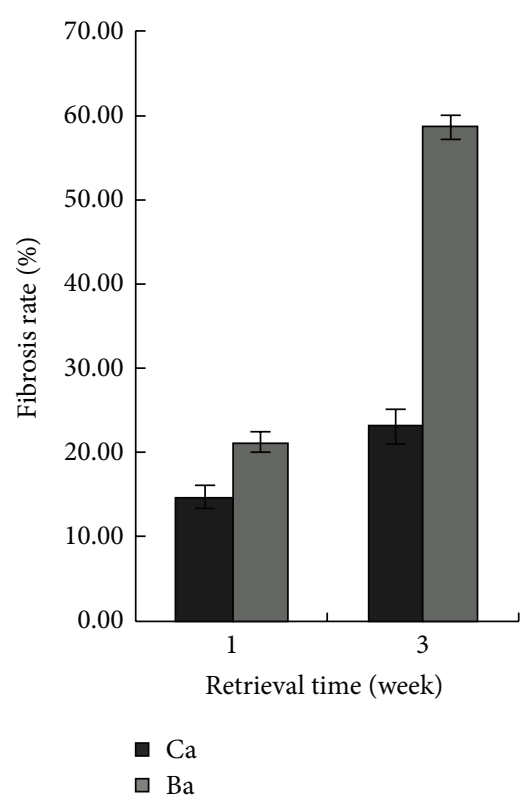

(a)

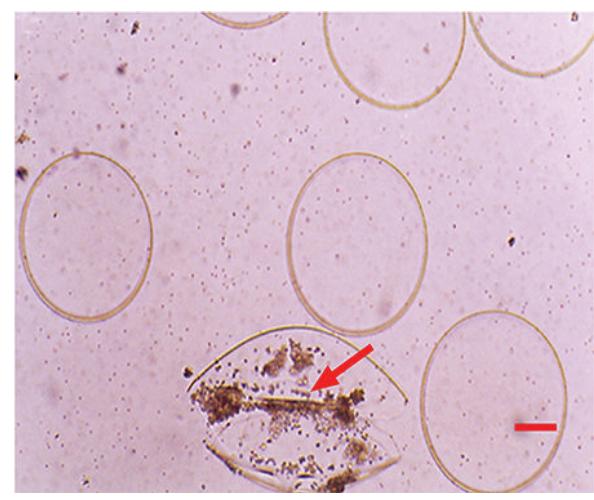

(b)

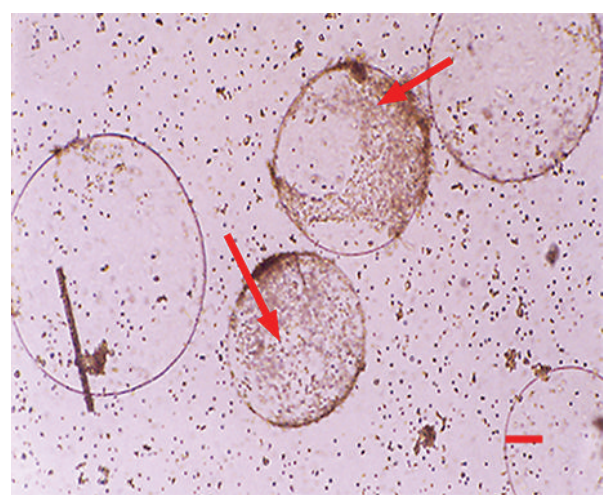

(c)

FIGURE 5: Biocompatibility of microcapsules. The same number of empty DPC-Ba and DPC-Ca microcapsules was introduced into the peritoneal cavity of mice and retrieved after 1 and 3 weeks for measurement of rate of fibrosis (a). One week after transplantation into the mouse peritoneal cavity, the retrieved $\mathrm{Ca}(\mathrm{b})$ and $\mathrm{Ba}(\mathrm{c})$ microcapsules showed increased fibrosis $(2.3 \%$ and $5.9 \%(P<0.01)$, resp.), with surrounding inflammatory cells. (Bar $=100 \mu \mathrm{m}$.)

for the multipotent nestin-positive stem cells in the hair follicle on follicle sensory-nerve growth and regeneration $[21,22]$. In addition, nestin-expressing multipotent stem cells were found in the fungiform papilla in the tongue; they showed typical markers of multiple cell types such as nerve cells, glial cells, and keratinocytes, indicating that nestin-expressing fungiform papilla cells and the nestinexpressing hair follicle stem cells have high similarity [23]. Finally, Gelfoam-histocultured whisker follicles were shown to produce growing pigmented and unpigmented hair shafts, suggesting that Gelfoam histoculture can support extensive hair-shaft growth as well as hair follicle sensory-nerve growth from isolated hair follicles for long periods of time. Therefore, Gelfoam histoculture of hair follicles allows prolonged evaluation of novel agents to promote hair growth [24]. It might be a good alternative 3D culture system choice.

The capability of DP cells to induce HF formation was suggested to be due to secreted factors such as cytokines [25].
Pluripotent stem cells expressing nestin have been identified in both bulge area and DP in hair follicle [26, 27]. The cells developed from bulge area have been proved to contain the pluripotency to different into other nonfollicle cells including neuron [27-32]. Indeed, the bulge area nestin-expressing stem cells seemed to be with better pluripotency than DP derived stem cells. The previous and present studies have tested the effect of DP cell transplantation in promoting hair follicle formation.

\section{Conclusions}

In conclusion, we have established a model to culture DPCs in $3 \mathrm{D}$ culture conditions. Both $\mathrm{Ba}$ and $\mathrm{Ca}$ microcapsules keep xenogenic DPCs in an immunoisolated environment and induce de novo $\mathrm{HF}$ formation before inflammatory cell aggregation. As a scaffold for DPCs, Ca microcapsule scaffolds were better compared with Ba scaffolds in terms of 


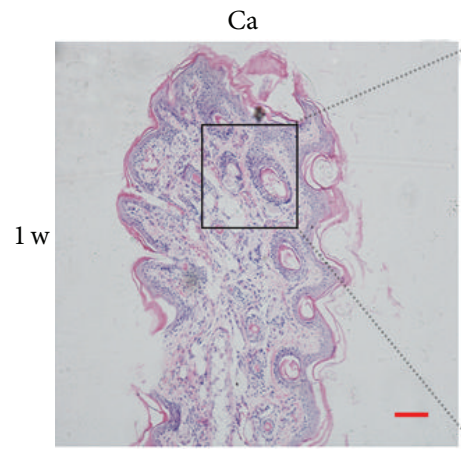

(a)

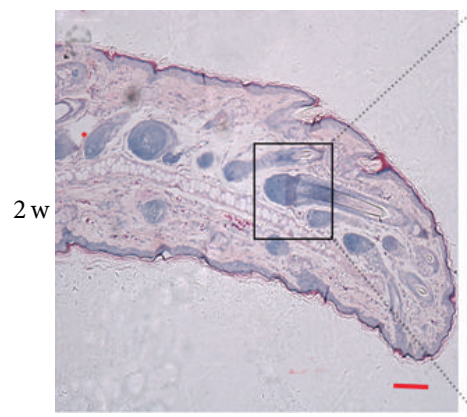

(e)

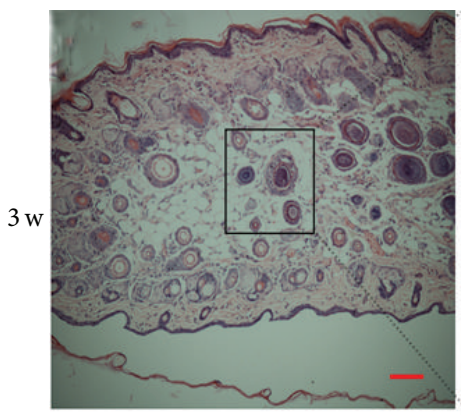

(i)

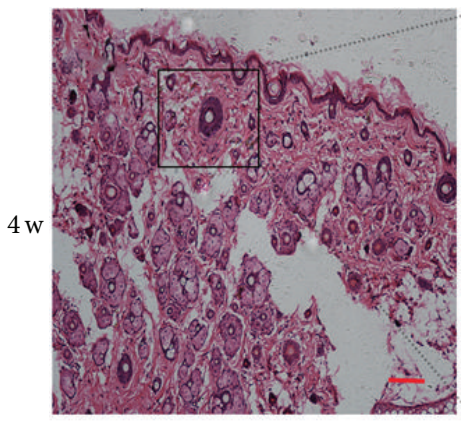

(m)

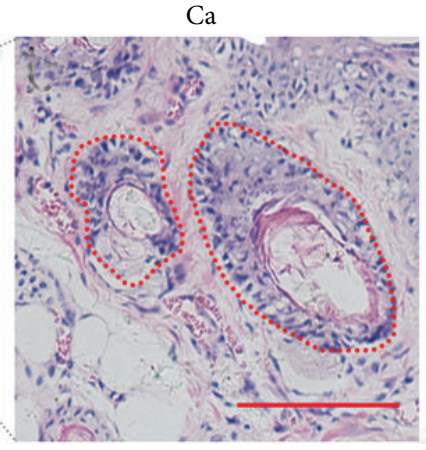

(b)

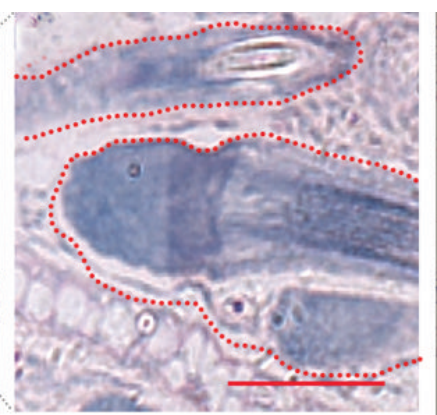

(f)

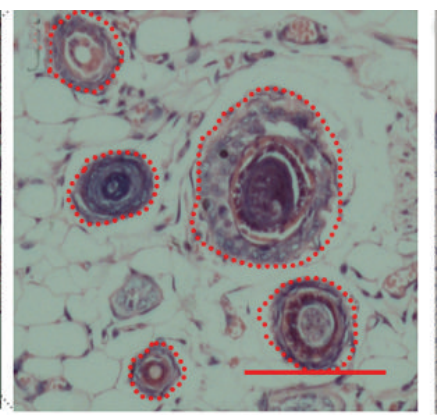

(j)

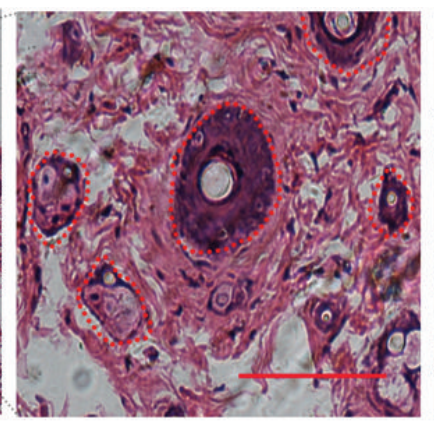

(n)

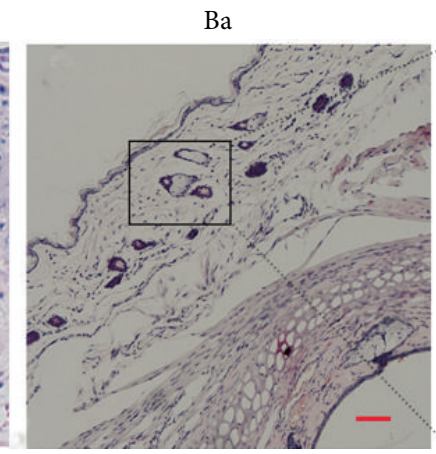

(c)

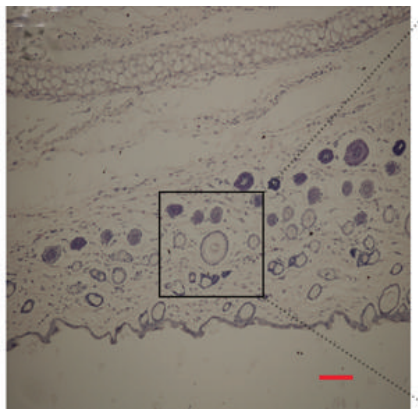

(g)

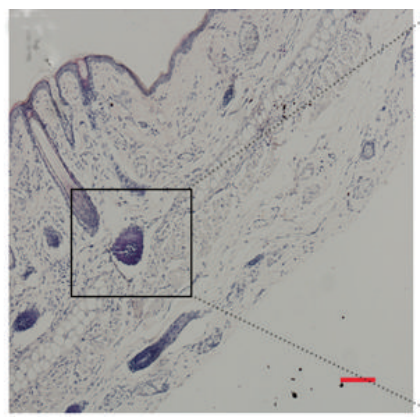

(k)

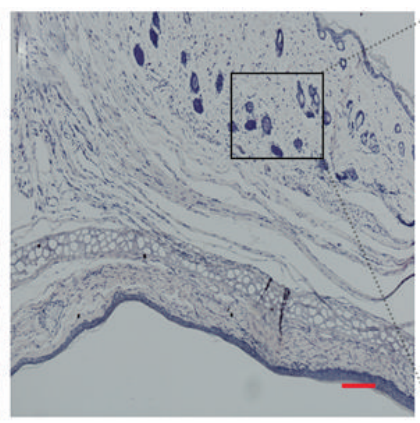

(o)

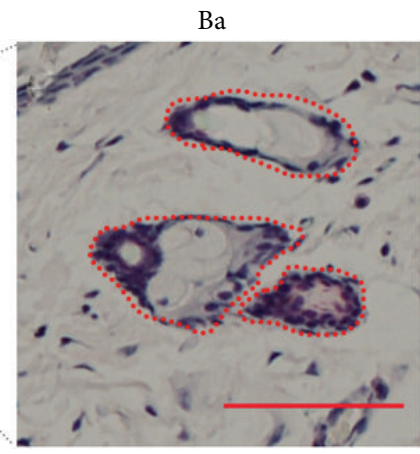

(d)

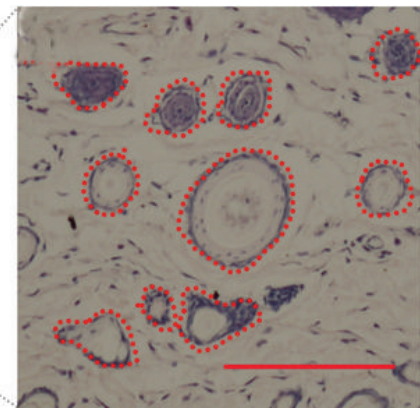

(h)

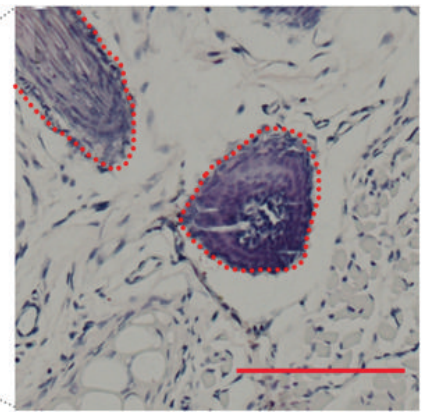

(1)

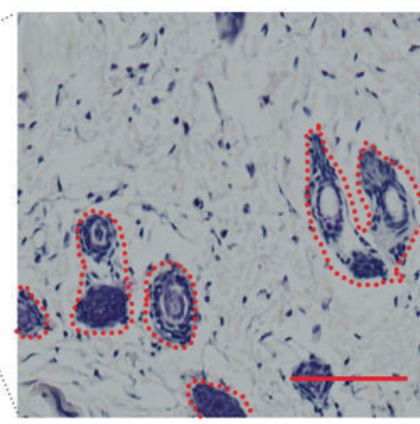

(p)

FIGURE 6: Short-term study of DPC-Ca and DPC-Ba microcapsules transplanted into rat ears. Large hair follicles formed after Ca microcapsule implantation at weeks 1-4 (a, b, e, f, i, j, m, and n). At 2 weeks, large DP formed near the transplanted site without the surrounding DPC microcapsule (e, f). No abnormal hair follicle structures were found in Ba microcapsules at 1 to 2 weeks after transplantation (c, $d$, $g$, and h). At 3 to 4 weeks, $\mathrm{Ba}(\mathrm{k}, \mathrm{l}, \mathrm{o}$, and $\mathrm{p})$ microcapsules produced large hair follicles but fewer compared with Ca (i, j, m, and n) microcapsules. $($ Bar $=100 \mu \mathrm{m}$.) 


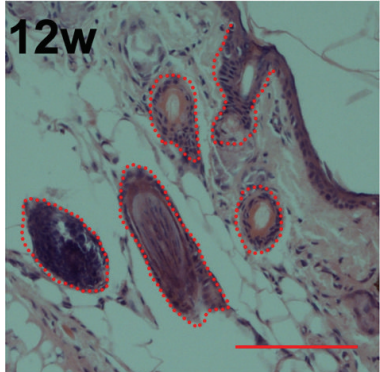

(a)

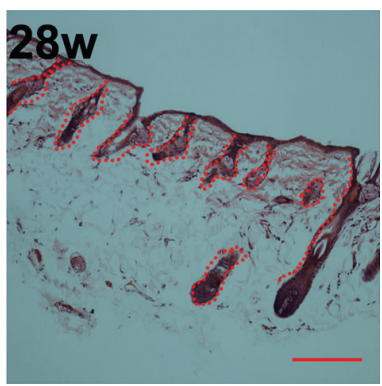

(e)

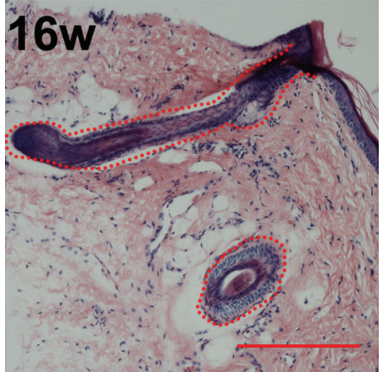

(b)

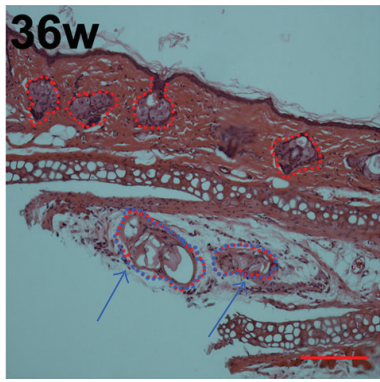

(f)

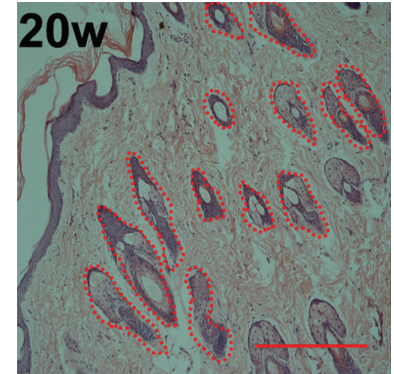

(c)

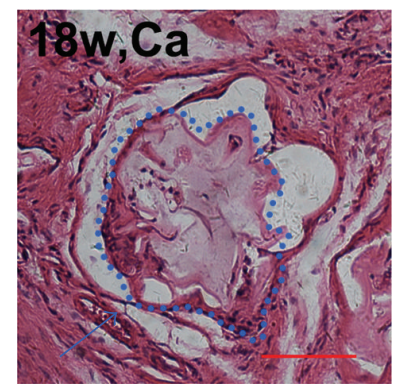

$(\mathrm{g})$

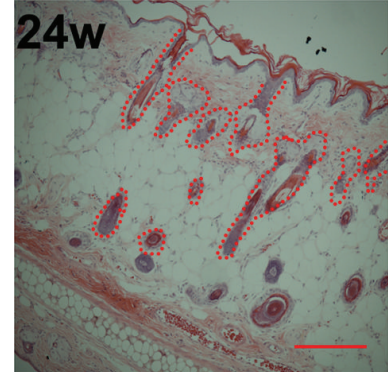

(d)

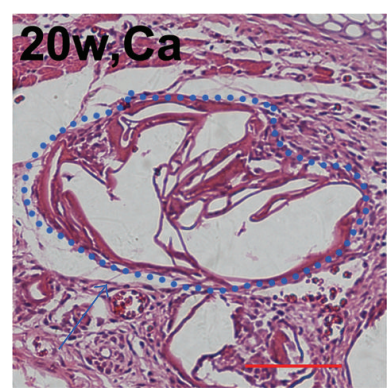

(h)

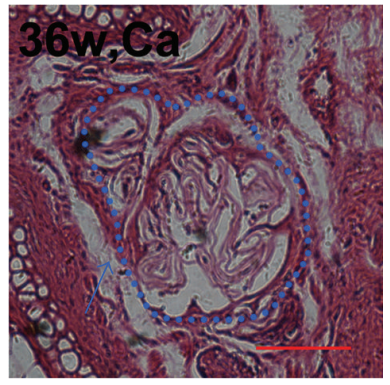

(i)

Figure 7: Long-term study of DPC-Ca microcapsules transplanted into rat ears and the histology of Ca microcapsules at different weeks. From 12 to 36 weeks, the number and size of large hair follicles decreased (a, b, c, d, e, and f). At 18 weeks, Ca microcapsules were found at the transplanted site, with no surrounding inflammatory cells (g). At 20 weeks, some inflammatory cells were around the microcapsules (h). At 36 weeks the number of inflammatory cells was reduced, with fibers around the microcapsules (i). (Bar $=100 \mu \mathrm{m}$.) Red circle: microcapsules and formed HFs. Blue circle and arrow: microcapsules surrounded associated with inflammatory cells.

biocompatibility, permeability, and cell viability. Implanted DPCs may provide important materials to induce HF reconstruction. Compared with other 3D culturing methods [17, 31, 32], the DPC-Ca microcapsules may have a significant advantage in xenotransplantation. Also the implanted DP on Ca microcapsule scaffolds can induce new and native DP regeneration and is fiber-wrapped after long-term transplantation.

\section{Competing Interests}

The authors declare that there are no competing interests regarding the publication of this paper.

\section{Authors' Contributions}

Yang Liu and Changmin Lin contributed equally to this work.

\section{Acknowledgments}

This research was supported by the National Natural Science Foundation of China (no. 81171832, no. 81071577, and no. 81372084), the Natural Science Foundation of Guangdong Province (no. S2011010004946), and the Science \& Technology Project of Guangdong Province (nos. 2010B080701065, 2011B080701067).

\section{References}

[1] M. P. Birch and A. G. Messenger, "Genetic factors predispose to balding and non-balding in men," European Journal of Dermatology, vol. 11, no. 4, pp. 309-314, 2001.

[2] D. Stough, K. Stenn, R. Haber et al., "Psychological effect, pathophysiology, and management of androgenetic alopecia in men," Mayo Clinic Proceedings, vol. 80, no. 10, pp. 1316-1322, 2005. 
[3] K. A. Horne, C. A. Jahoda, and R. F. Oliver, "Whisker growth induced by implantation of cultured vibrissa dermal papilla cells in the adult rat," Journal of Embryology and Experimental Morphology, vol. 97, pp. 111-124, 1986.

[4] M. Inamatsu, T. Matsuzaki, H. Iwanari, and K. Yoshizato, "Establishment of rat dermal papilla cell lines that sustain the potency to induce hair follicles from afollicular skin," The Journal of Investigative Dermatology, vol. 111, no. 5, pp. 767-775, 1998.

[5] C. A. B. Jahoda, K. A. Horne, and R. F. Oliver, "Induction of hair growth by implantation of cultured dermal papilla cells," Nature, vol. 311, no. 5986, pp. 560-562, 1984.

[6] C. A. B. Jahoda, A. J. Reynolds, and R. F. Oliver, "Induction of hair growth in ear wounds by cultured dermal papilla cells," The Journal of Investigative Dermatology, vol. 101, no. 4, pp. 584-590, 1993.

[7] A. Osada, T. Iwabuchi, J. Kishimoto, T. S. Hamazaki, and H. Okochi, "Long-term culture of mouse vibrissal dermal papilla cells and de novo hair follicle induction," Tissue Engineering, vol. 13, no. 5, pp. 975-982, 2007.

[8] H. A. Pasolli, "The hair follicle bulge: a niche for adult stem cells," Microscopy and Microanalysis, vol. 17, no. 4, pp. 513-519, 2011.

[9] K. S. Stenn and G. Cotsarelis, "Bioengineering the hair follicle: fringe benefits of stem cell technology," Current Opinion in Biotechnology, vol. 16, no. 5, pp. 493-497, 2005.

[10] C.-M. Lin, Y. Li, Y.-C. Ji, H. Keng, X.-N. Cai, and J.-K. Zhang, "Microencapsulated human hair dermal papilla cells: a substitute for dermal papilla?" Archives of Dermatological Research, vol. 300, no. 9, pp. 531-535, 2008.

[11] C.-M. Lin, Y. Li, Y.-C. Ji, K. Huang, X.-N. Cai, and G.Q. Li, "Induction of hair follicle regeneration in rat ear by microencapsulated human hair dermal papilla cells," Chinese Journal of Traumatology, vol. 12, no. 1, pp. 49-54, 2009.

[12] H. Zimmermann, D. Zimmermann, R. Reuss et al., "Towards a medically approved technology for alginate-based microcapsules allowing long-term immunoisolated transplantation," Journal of Materials Science: Materials in Medicine, vol. 16, no. 6, pp. 491-501, 2005.

[13] E. G. Sherman, P. J. Antonelli, and R. Tran-Son-Tay, "Development of a calcium alginate tympanostomy tube," Laryngoscope, vol. 120, no. 12, pp. 2473-2477, 2010.

[14] S. K. Koo, S. C. Kim, Y. M. Wee et al., "Experimental microencapsulation of porcine and rat pancreatic islet cells with air-driven droplet generator and alginate," Transplantation Proceedings, vol. 40, no. 8, pp. 2578-2580, 2008.

[15] Y. Li, G. Q. Li, C. M. Lin, and X. N. Cai, “One-step collagenase I treatment: an efficient way for isolation and cultivation of human scalp dermal papilla cells," Journal of Dermatological Science, vol. 37, no. 1, pp. 58-60, 2005.

[16] C. A. B. Jahoda and R. F. Oliver, "Vibrissa dermal papilla cell aggregative behaviour in vivo and in vitro," Journal of Embryology and Experimental Morphology, vol. 79, pp. 211-224, 1984.

[17] C.-H. Hsieh, J.-L. Wang, and Y.-Y. Huang, "Large-scale cultivation of transplantable dermal papilla cellular aggregates using microfabricated PDMS arrays," Acta Biomaterialia, vol. 7, no. 1, pp. 315-324, 2011.

[18] S. A. Abbah, W. W. Lu, S. L. Peng et al., "Extracellular matrix stability of primary mammalian chondrocytes and intervertebral disc cells cultured in alginate-based microbead hydrogels," Cell Transplantation, vol. 17, no. 10-11, pp. 1181-1192, 2008.
[19] H. J. Kong, D. Kaigler, K. Kim, and D. J. Mooney, “Controlling rigidity and degradation of alginate hydrogels via molecular weight distribution," Biomacromolecules, vol. 5, no. 5, pp. 17201727, 2004.

[20] J. Duong, S. Mii, A. Uchugonova, F. Liu, A. R. Moossa, and R. M. Hoffman, "Real-time confocal imaging of trafficking of nestinexpressing multipotent stem cells in mouse whiskers in longterm 3-D histoculture," In Vitro Cellular and Developmental Biology-Animal, vol. 48, no. 5, pp. 301-305, 2012.

[21] S. Mii, J. Duong, Y. Tome et al., "The role of hair follicle nestinexpressing stem cells during whisker sensory-nerve growth in long-term 3D culture," Journal of Cellular Biochemistry, vol. 114, no. 7, pp. 1674-1684, 2013.

[22] S. Mii, F. Uehara, S. Yano et al., "Nestin-expressing stem cells promote nerve growth in long-term 3-dimensional gelfoam(R)supported histoculture," PLoS ONE, vol. 8, no. 6, Article ID e67153, 2013.

[23] S. Mii, Y. Amoh, K. Katsuoka, and R. M. Hoffman, "Comparison of nestin-expressing multipotent stem cells in the tongue fungiform papilla and vibrissa hair follicle," Journal of Cellular Biochemistry, vol. 115, no. 6, pp. 1070-1076, 2014.

[24] W. Cao, L. Li, S. Mii et al., "Extensive hair-shaft elongation by isolated mouse Whisker Follicles in very long-term Gelfoam ${ }^{\circledR}$ histoculture," PLOS ONE, vol. 10, no. 9, Article ID e0138005, 2015.

[25] W. Filsell, J. C. Little, A. J. Stones, S. P. Granger, and S. A. Bayley, "Transfection of rat dermal papilla cells with a gene encoding a temperature-sensitive polyomavirus large $\mathrm{T}$ antigen generates cell lines retaining a differentiated phenotype," Journal of Cell Science, vol. 107, part 7, pp. 1761-1772, 1994.

[26] L. Li, J. Mignone, M. Yang et al., "Nestin expression in hair follicle sheath progenitor cells," Proceedings of the National Academy of Sciences of the United States of America, vol. 100, no. 17, pp. 9958-9961, 2003.

[27] Y. Amoh, L. Li, K. Katsuoka, and R. M. Hoffman, "Multipotent hair follicle stem cells promote repair of spinal cord injury and recovery of walking function," Cell Cycle, vol. 7, no. 12, pp. 1865$1869,2008$.

[28] Y. Amoh, L. Li, K. Katsuoka, S. Penman, and R. M. Hoffman, "Multipotent nestin-positive, keratin-negative hairfollicle bulge stem cells can form neurons," Proceedings of the National Academy of Sciences of the United States of America, vol. 102, no. 15, pp. 5530-5534, 2005.

[29] Y. Amoh, L. Li, R. Campillo et al., "Implanted hair follicle stem cells form Schwann cells that support repair of severed peripheral nerves," Proceedings of the National Academy of Sciences of the United States of America, vol. 102, no. 49, pp. 17734-17738, 2005.

[30] A. Uchugonova, J. Duong, N. Zhang, K. König, and R. M. Hoffman, "The bulge area is the origin of nestin-expressing pluripotent stem cells of the hair follicle," Journal of Cellular Biochemistry, vol. 112, no. 8, pp. 2046-2050, 2011.

[31] S. Ihara, M. Watanabe, E. Nagao, and N. Shioya, "Formation of hair follicles from a single-cell suspension of embryonic rat skin by a two-step procedure in vitro," Cell and Tissue Research, vol. 266, no. 1, pp. 65-73, 1991.

[32] T.-H. Young, C.-Y. Lee, H.-C. Chiu, C.-J. Hsu, and S.-J. Lin, "Self-assembly of dermal papilla cells into inductive spheroidal microtissues on poly(ethylene-co-vinyl alcohol) membranes for hair follicle regeneration," Biomaterials, vol. 29, no. 26, pp. 35213530, 2008. 


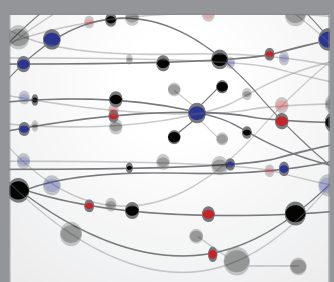

The Scientific World Journal
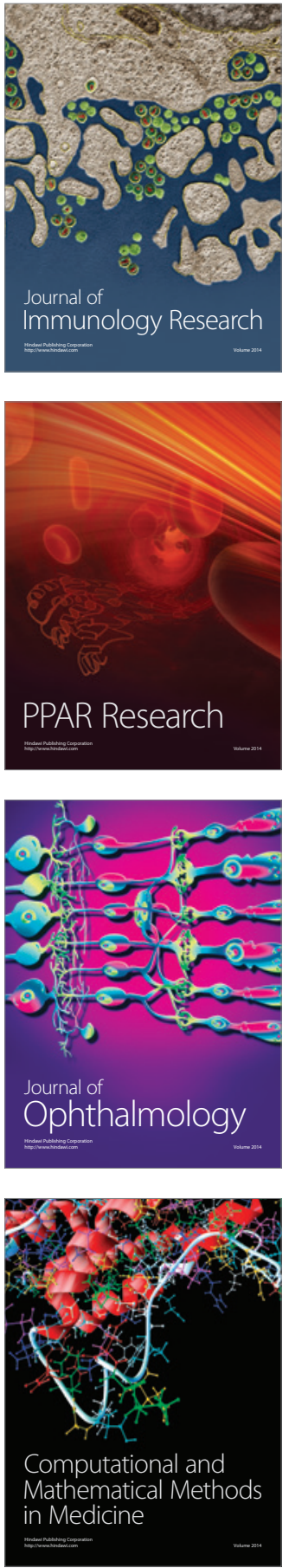

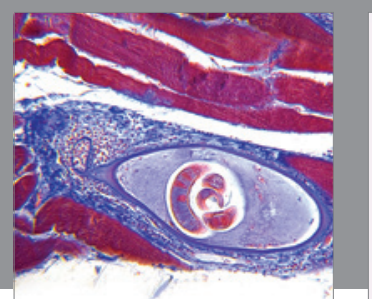

Gastroenterology Research and Practice

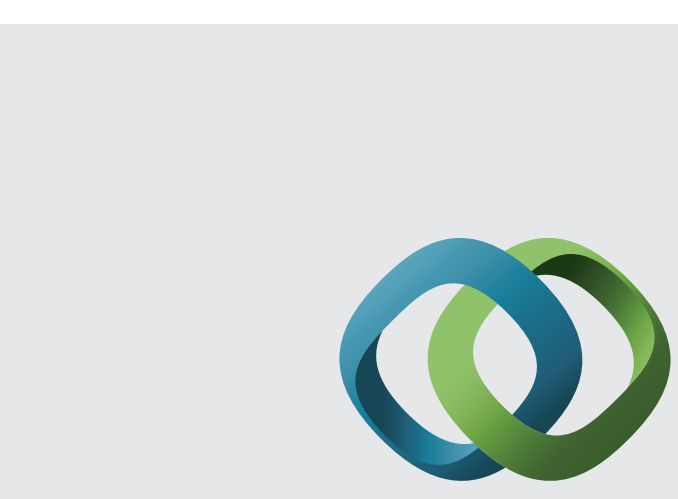

\section{Hindawi}

Submit your manuscripts at

http://www.hindawi.com
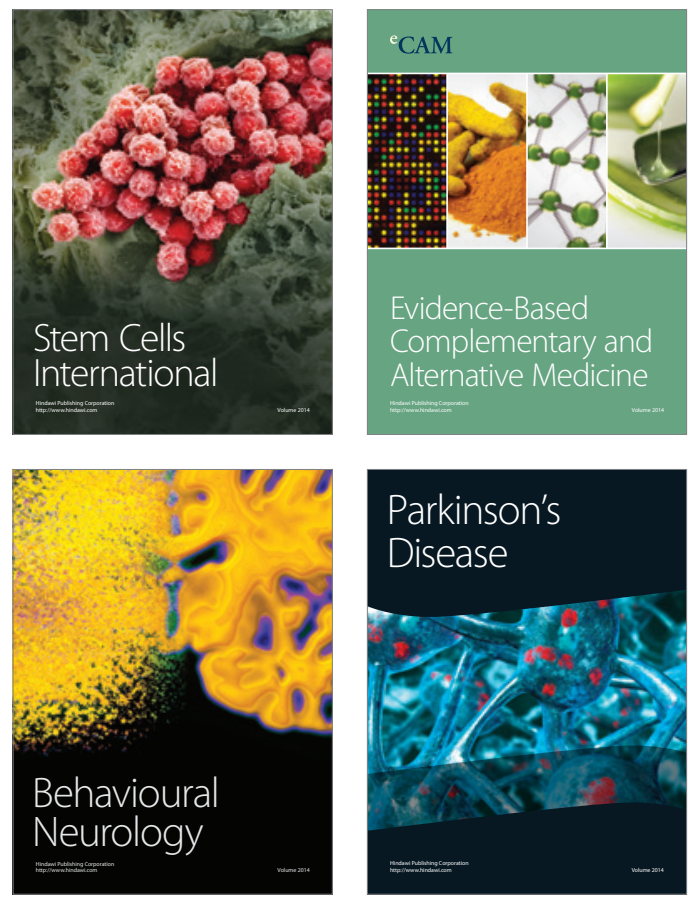
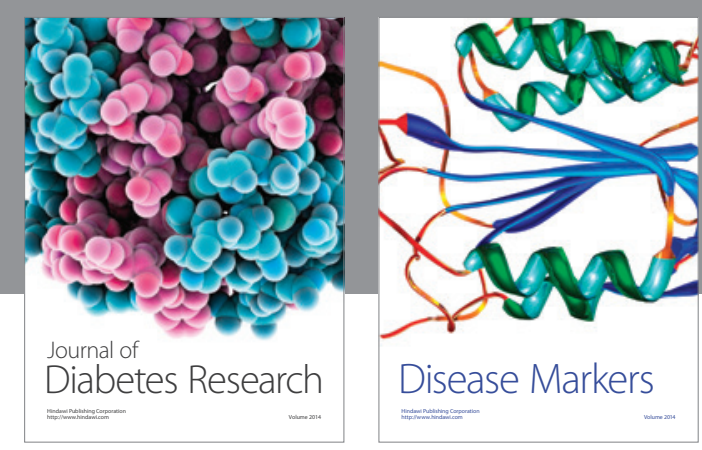

Disease Markers
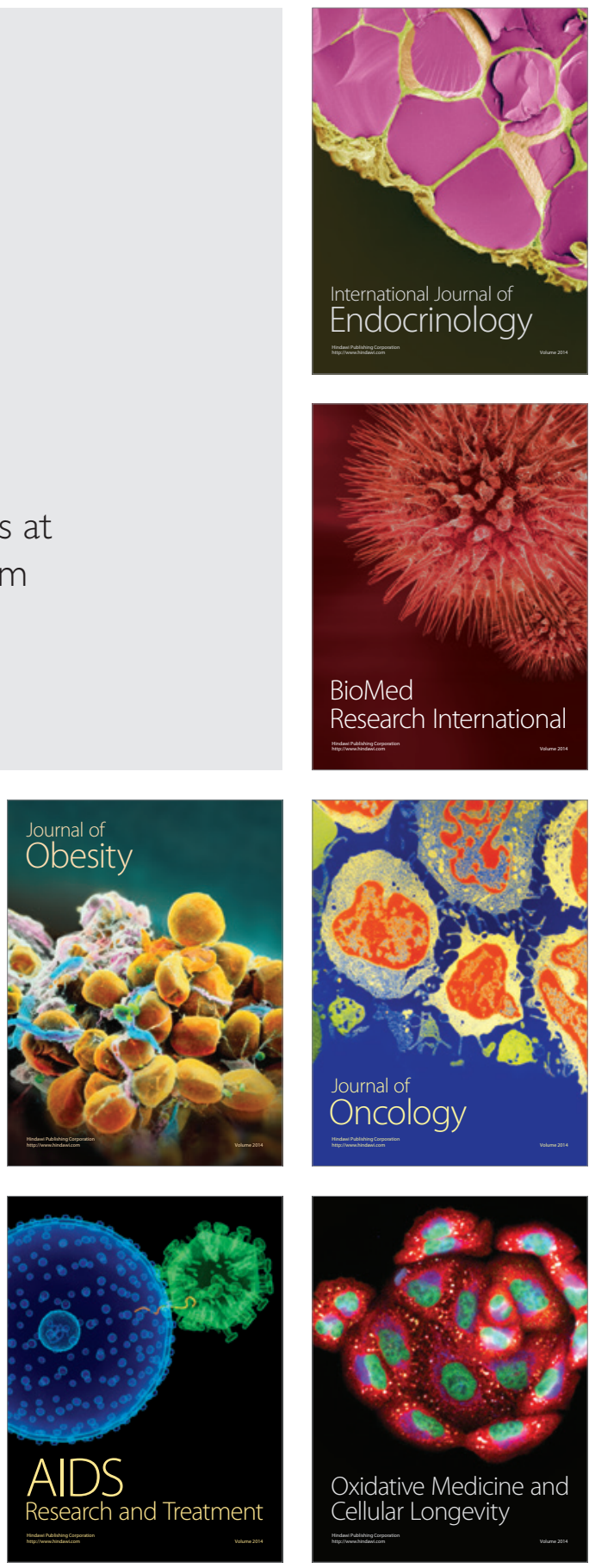